\title{
De viva y vieja voz: Celestina por sí misma
}

\author{
Ximena Gómez Goyzueta \\ Universidad Autónoma de Aguascalientes
}

Celestina es el vivo retrato de la maldad. Esta afirmación se impone en una lectura inicial de la Tragicomedia de Calisto y Melibea. La manipulación de Calisto, la corrupción de Pármeno, el conjuro demoniaco, el negocio mercantil de Melibea, la philocaptio y la codicia son pruebas suficientes para considerar seriamente a Celestina como un ser maligno. Esta maldad no sólo se caracteriza por los actos. Jacobo Sanz (1994) y Lillian von der Walde (2007) han demostrado que el retrato de «aquella vieja de la cuchillada» como "vieja barbuda", "reúne elementos tópicos de índole negativa asentados en la tradición tanto culta como popular, que bien la caracterizan, y provocan en los receptores la idea del mal» (139). El bagaje simbólico del saber científico medieval y su herencia antigua son la base utilizada por estos críticos para estudiar la figura celestinesca. Para este saber, "los atributos del individuo, así como sus vicios y virtudes se vuelven [...] reconocibles mediante el cuerpo» (129). En la caracterización de "vieja barbuda", Sanz ve un rasgo clave y revelador de la relación de Celestina con el mundo demoniaco. Para von der Walde, «[su] rostro abyecto representa, por una parte [el] lado obscuro y temido de la sociedad, y por otra, el conjunto de conceptuaciones y prejuicios de una época». (139). A su vez, estas descripciones bosquejan a las mujeres que practicaban el mismo oficio de la vieja salmantina, a saber, el oficio de la "hechicera-alcahueta».

Si aceptáramos que Celestina es un ser maligno, el siguiente cuestionamiento de Alan Deyermond podría responderse afirmativamente: «[...] habrá que preguntarse si la representación de la hechicería/brujería de Celestina $[\ldots]$ se debe explicar en términos de la represión misógina» (2008: 80). Efectivamente, Celestina refleja las creencias medievales y renacentistas de "la bruja deforme y macilenta, aliada inconfundible del diablo» (Cohen 2003: 46). No obstante, Deyermond señala que lo verdaderamente intrigante es el poder de la sociedad femenina creada por Claudina y Celestina (83). Esta pequeña sociedad — que, por cierto, comienza con Claudina, pasa por la abuela de Elicia, y que Celestina hereda a Elicia y Areúsa - se impone temporal y espacialmente en la Tragicomedia sobre la sociedad patriarcal de Calisto y Pleberio: temporalmente, por 
esta sucesión matrilineal frente a la extinta prole de Calisto y de Pleberio; espacialmente, porque así como Celestina y las mochachas gobiernan en su casa, la alcahueta logra la transgresión de la casa de Pleberio y, por consiguiente, también la transgresión del cuerpo de Melibea.

Las observaciones de Deyermond son acertadas. Pero hay otro aspecto fundamental que no permite que la perspectiva misógina caiga en su totalidad sobre Celestina: el arte de este diálogo salmantino. Los personajes se desenlazan de sus moldes tópicos gracias a que cada uno posee un punto de vista propio, que expone y se pone en crisis ante el interlocutor en curso o incluso ante sí mismos. Con ello, la alcahueta aparece distanciada de una intención autoral explícita. La lena no sólo es descrita por los otros personajes según esta tópica, sino que también se piensa a sí misma, actúa y reacciona de manera compleja y contradictoria frente al punto de vista de los demás personajes. De esta forma, aparece una doble perspectiva del personaje: por un lado, la fuerte presencia del retrato celestinesco a partir de la tradición misógina es un hecho; por otro lado, es innegable la libertad de acción que adquiere el personaje gracias al perspectivismo del diálogo celestinesco. Este doble tamiz encierra una intención autoral inquietante que se puede explicar así: si el autor se distancia de su personaje y le da libertad de acción en un diálogo que pareciera determinarlo ideológicamente, entonces parece estarse dirigiendo, por lo menos, a dos receptores posibles: a aquél que asumirá a Celestina como el retrato de los seres malignos existentes en una sociedad que los repudia. O también a aquel receptor, "el lector discreto", que logre identificar esta distancia y discierna entre una Celestina, resultado de la imaginación misógina, y una Celestina que plantea una posición ambigua frente a este imaginario propio de la España de Rojas. Propongo, pues, el análisis del desarrollo de esta doble perspectiva. Para ello, tomo en cuenta una de las características más notables de la alcahueta: la vejez.

Así es nombrada Celestina por primera vez en el Argumento de la Tragicomedia: «Por solicitud del $\mathrm{p}[\mathrm{u}]$ ngido Calisto, vencido el casto propósito della, ent[re]viniendo Celestina, mala y astuta muger, con dos sirvientes del vencido Calisto, engañados y por ésta tornados desleales, presa su fidelidad con anzuelo de cobdicia y de deleyte [...]». ${ }^{1}$ La siguiente mención aparece en el Argumento del primer auto: «[Calisto] habló con un criado suyo llamado Sempronio, el qual, [...] le endereçó a una vieja llamada Celestina» (I, 210).

En el Argumento de la obra, se apuntan la labia de Celestina y su poder para mover a lujuria: se trata de una mala y astuta mujer, que engaña y engancha a la gente con la codicia y el sexo. En el Argumento del primer au-

1.- (Argumento: 208). Todas las referencias a la Celestina provienen de la edición de Peter E. Russell, de Cásicos Castalia del 2001 que consigno en la bibliografía. De aquí en adelante, cada vez que cite el texto anotaré entre paréntesis el número de auto y la página correspondientes. 
to se puntualiza que se trata de una «vieja». Estas referencias no están en voz ni de los personajes ni de Celestina, sino de los autores. Podríamos pensar hasta aquí que Celestina pertenece a la estirpe de las «falsas mugeres hechizeras» evocadas en la "Carta del autor a un su amigo». Fray Martín de Castañega en su Tratado de las supersticiones y hechicerías afirma que la vejez, acompañada de sus respectivas carencias, hace a las mujeres proclives a entrar en tratos con el demonio: "E más son de las mujeres viejas y pobres, que de las mozas y ricas, porque como después de viejas los hombres no hacen caso dellas, tienen recurso al demonio, que cumple sus apetitos [...].» (Castañeda apud Blanco 64). Así, la mención general de las "falsas mugeres hechizeras», se asocia directamente a las adjetivaciones que Celestina recibe en los Argumentos iniciales. En suma, hasta ahora vemos a la lena a través de los ojos de los autores.

Estos calificativos coinciden con la primera mención de Celestina en el diálogo: Sempronio habla a Calisto de ella como el mejor remedio para alcanzar a Melibea. Enuncia lo siguiente el criado:

[...] Días ha que conozco, en fin desta vecindad, una vieja barbuda que se dize Celestina, hechizera, astuta, sagaz en quantas maldades hay. Entiendo que pasan de cinco mil virgos los que se han hecho y desecho por su auctoridad en esta cibdad. A las duras peñas promoverá y provocará a luxuria si quiere (I, 234).

Con estas palabras, los defectos malignos de Celestina se convierten en los atributos que Calisto necesita en ella para alcanzar a Melibea. De su lado, Pármeno describe a la alcahueta casi con las mismas características, pero con un objetivo distinto del de Sempronio: advertir a Calisto sobre la peligrosidad de acudir a una "[...] flaca puta vieja» que, según él, era una "puta alcoholada", que "tenía seys oficios, conviene a saber: labrandera, perfumera, maestra de fazer afeytes y de fazer virgos, alcahueta y un poquito hechizera» (I, 242), y que, además, le recuerda Pármeno a Celestina, "[...] olías a vieja».

De un momento a otro, y sin que Celestina haya aparecido aún, palabras similares adquieren significados distintos, pero suficientes para que Calisto decida cómo quiere ver a Celestina: como una "vieja barbuda», maestra en artes amatorias, o como "puta vieja», corruptora de jóvenes doncellas. Queda claro que el joven caballero elige la primera. Aunque estos sentidos de la vejez de Celestina abundan en el diálogo, no son los únicos.

Al utilizar los criados dos calificativos de carga negativa para Celestina, "vieja barbuda» $\mathrm{y}$ "puta vieja», la alcahueta sigue estando en el plano de la maldad con que se le presentó en el prólogo y en los Argumentos, y Calisto lo sabe muy bien. Es de notar, por ejemplo, su reacción al referirse a Celestina después de las advertencias de Pármeno, apenas en el segundo auto: "CAL.- Assí Pármeno, di más deso, que me agrada, pues mejor me 
parece quanto más la desalabas. Cumpla conmigo y emplúmenla la quarta [vez]» (II, 274). Calisto ya está al tanto del tipo de mujer que es Celestina. Podemos pensar, entonces, que aquellas ocasiones en que la alaba ridículamente en su presencia, no es más que una estrategia para seguir gozando del favor de la vieja. Algunos de estos epítetos son: «vieja honrrada», "notable mujer», "reverenda persona», «vejez virtuosa», "virtud envejecida", "O mi señora, mi madre, mi consoladora», etc.

Para terminar con este lado de la vejez de Celestina, resalto un elemento más que se une a los dos puntos de vista de los criados sobre ella: el de su fama popular. Tanto Sempronio como Pármeno la describen no sólo por ellos mismos, también por voz de una ciudad que la conoce muy bien. Afirma Sempronio: "Entiendo que pasan de cinco mil virgos los que se han hecho y desecho por su auctoridad en esta cibdad» (I, 234). En otras palabras, Celestina goza de esta fama. O bien, recordemos en voz de Pármeno aquella descripción del eco que se oye de ella en la ciudad: "puta vieja», "es nombrada y por tal título conocida». De la misma manera, Pármeno cuenta a Calisto cómo es que Celestina, "[...] la más antigua y puta [vieja] que fregaron sus espaldas en todos los burdeles» (I, 251), es necesitada por todos en la ciudad: "iQué trafagos, si piensas, trýa! Fazíase física de niños, tomava estambre de unas casas, dávalo a filar en otras por achaque de entrar en todas. Las unas '¡madre acá!', las otras '¡madre acullá!', ‘'cata la vieja!', 'iya viene el ama!' — de todas muy conocida» (I, 242). Por otro lado, Lucrecia también participa de informar al lector/oidor, y por supuesto de recordarle a Alisa la fama de Celestina: «jesú, señora! Más conoscida es esta vieja que la ruda. No sé cómo no tienes memoria de la que empicotaron por hechizera, que vendía las moças a los abades y descansava mil casados» (Iv, 303). Así, en esta primera configuración de Celestina, tenemos tres puntos de vista coincidentes sobre la estimación de su vejez: el de los autores, el de los criados y el de la ciudad que, además de conocerla, le ha dado fama.

Veamos ahora cómo se comporta Celestina frente a estas consideraciones. La alcahueta se concibe en su vejez así: "pecadora vieja», "vieja», «vieja Celestina», "flaca vieja», "puta vieja», "vieja experimentada", "los ancianos somos llamados padres, y los buenos padres aconsejan a sus hijos», "la vejez no es sino mesón de enfermedades», «No me castigues, por Dios, a mi vegez; no me maltrates», "no amengües mis canas", "soy una vieja cual Dios me hizo", "a las viejas nunca nos fallecen necesidades», "esta pobre vieja». Celestina concibe su vejez como sinónimo de pecado, maestría, debilidad, putería, experiencia, bondad, prudencia, enfermedad, falta de respeto, dignidad, carencias, necesidad, humildad. Para fines del análisis, agrupo estos adjetivos en tres campos semánticos distintos: el primero se relaciona con virtudes, a saber: la maestría, la experiencia, la prudencia, la bondad y la dignidad; el segundo, con vicios: la flaqueza espiritual, por tanto, el pecado y la putería; el tercero, con la vulnerabili- 
dad: mala salud, pobreza, necesidad y propensión a la falta de respeto. La relatividad del tiempo en la vejez de Celestina se mueve indistintamente por los tres campos semánticos, pues, como sabemos, es un aspecto más o menos indefinido en la vida de la vieja durante todo el diálogo.

La alcahueta manipula su condición de vieja con cada uno de estos campos, utilizándolos por separado o mezclándolos según la situación dialógica en que se encuentre. Cada característica, a su vez, es utilizada en momentos específicos para transformar constantemente la semántica. Así, Celestina crea un cerco de ambigüedad alrededor de su persona. Sus intenciones se ensombrecen y ni los dialogantes ni el receptor llegan a saber quién es realmente: el sentido de verdad o mentira en su boca se obscurece, con excepción al momento de su muerte, que estudiaremos más adelante. Veámosla ejecutar estos ardides.

$\mathrm{Al}$ inicio del primer encuentro con Melibea, Celestina abre el diálogo oponiendo los placeres de la juventud con la vejez. Esta oposición adquiere tres significados distintos que veremos a continuación. La alcahueta comienza su persuasión con el carpe diem:

$$
\begin{aligned}
& \text { CEL.- [...] Dios la dexe gozar su noble juventud y florida } \\
& \text { mocedad, que es el tiempo en que más plazeres y mayo- } \\
& \text { res deleytes se alcanzarán. Que, a la mi fe, la vejez no es } \\
& \text { sino mesón de enfermedades, posada de pensamientos, } \\
& \text { amiga de renzillas, congoxa continua, llaga incurable, } \\
& \text { manzilla de lo pasado (IV, 306). }
\end{aligned}
$$

Celestina usa este argumento, principalmente, para convencer a Melibea de disfrutar de los placeres sexuales en la juventud. Sin embargo, la conclusión de su tesis la pone en la mira de la noble doncella:
MEL.- Espantada me tienes con lo que has hablado. In- dicio me dan tus razones que te aya visto otro tiempo. Dime madre, ¿eres tú Celestina, la que solía morar a las tenerías cabe el río?
CEL.- Señora, hasta que Dios quiera.
MEL.- Vieja te has parado. Bien dices que los días no se van en balde. Assí goze de mí, no te conociera sino por essa señaleja de la cara. Figúraseme que eras hermosa. Otra pareces. Muy mudada estás. (Iv, 309)

Vulnerable ante esta osadía, Celestina justifica el pesar de su deterioro y su vejez con la relatividad del paso del tiempo. Oculta, por supuesto, la idea que subyace a su argumento sobre los placeres de juventud; a saber, el deterioro prematuro en la vejez es causa de los excesos durante la juventud. Escuchémosla: 
CEL.- Señora, ten tú el tiempo que no ande, terné yo mi forma que no se mude ¿¿No has leýdo que dizen: «verná el día que en el espejo no te conozcas». Pero también yo encanecí temprano. [...] Que de cuatro hijas que parió mi madre, yo fui la menor. Mira cómo no só [tan] vieja como me juzgan. (Iv, 310)

Como se observa, la connotación negativa que da Celestina a la vejez está dirigida a la persuasión de Melibea. Significa la clausura del gozo, y existe la posibilidad de que el paso del tiempo haga estragos en las personas a una edad temprana. Por lo tanto, plantea Celestina, hay que vivir el momento. Con estas afirmaciones, la lena tiene que aceptar ante Melibea que esta connotación de vejez le corresponde. Sin embargo, el sentido de la segunda afirmación, los anticipados estragos del tiempo, es caritativo para ella. Aunque Celestina esté deteriorada físicamente, es más joven. Esa idea de juventud, por supuesto le interesa más a ella que a Melibea. De cualquier forma, queda la duda de si la alcahueta dice la verdad en este pasaje, pues, como sabemos, la inexactitud sobre su edad a lo largo del diálogo es patente.

Ahora bien, en esta situación aparecen relacionados dos de los campos semánticos que propuse, el de los vicios y el de la vulnerabilidad. Éstos corresponden, justamente, al argumento que Celestina omite: la causa de la vejez prematura es el exceso en la juventud. Y así es: debido a la flaqueza de espíritu, por tanto, al pecado y a la putería, la vulnerabilidad en la vejez acecha a la alcahueta, en este caso con la "falta de respeto" de Melibea al tratarla de vieja arrugada y fea. A pesar de esto, Celestina cumple su cometido, pues Melibea parece no sospechar sobre este juego de sentidos entre juventud y vejez, mucho menos se percata de la omisión señalada, $y$, por consiguiente, de que Celestina podría convertirse en su propio reflejo si sigue sus consejos. Así, la lena manipula el sentido de su vejez para afectar los jóvenes oídos de Melibea en su favor. Esto lo hace con dos afirmaciones explícitas: la primera, la vejez es mala y la juventud es buena; la segunda, aunque joven, yo represento esa vejez mala; $y$, además, con una afirmación implícita: la vejez es mala si la juventud se vive con excesos. En suma, en esta sección hemos podido ver tres formas en las que Celestina manipula el sentido de su vejez. En el siguiente apartado, tenemos el preámbulo de la vieja a la primera ida a casa de Melibea.

Sempronio advierte a Celestina sobre los peligros de transgredir la casa de Pleberio. La lena ofrece tres razones para garantizar su éxito: la paga, el deseo sexual en las mujeres y la experiencia en su oficio de hechicera/ alcahueta. Veamos cómo se relaciona esto con su vejez y con los campos semánticos propuestos. Escéptico, Sempronio cuestiona a Celestina. Ella responde con la primera razón: la paga que está recibiendo ya. Para este momento, Calisto le ha dado cien monedas de oro. 
SEM.- ¿Pues crees que podrás alcançar algo de Melibea? CEL.- Lo que yo al presente veo te diré: Melibea es hermosa. Calisto loco y franco. Ni a él penará gastar, ni a mí andar. ¡Bulla moneda y dure el pleito lo que durare! Todo lo puede el dinero (III, 286).

La segunda razón no sólo tiene que ver con el deseo sexual de las doncellas guardadas como Melibea; éste afecta a las mujeres, en general, incluida la propia Celestina.

CEL.- [...] Camino es, hijo, que nunca me harté de andar; nunca me vi cansada. Y aun, así vieja como soy, sabe Dios mi buen deseo. ¡Cuánto más estas que hierven sin fuego! [...] No te sabré decir lo mucho que obra en ellas aquel dulçor que les queda de los primeros besos de quien aman. Son enemigas del medio; contino están posadas en los estremos (III, 287-288).

La tercera razón, la experiencia en el oficio, deambula por toda la discusión con Sempronio: "Que aunque esté brava Melibea, no es ésta, si a Dios ha plazido, la primera a quien yo he hecho cacarear», "[...] aunque al presente la ruegue, al fin me ha de rogar, aunque al principio me amenaze, al cabo me ha de halagar", "iAun si quisieses avisar a Celestina en su oficio! Pues quando tú naciste, ya comía yo pan con corteza.» Los tres campos semánticos se hacen presentes en las razones de Celestina: la primera razón corresponde al campo de la vulnerabilidad, pues sabemos que la alcahueta tiene necesidad de dinero porque su oficio no le alcanza para vivir bien. Ella misma lo confiesa así cuando viene de su primer triunfo: «Pues, alégrate, vieja; que más sacarás deste pleito, que de quinze virgos que renovaras». La segunda razón corresponde a los vicios: el deseo sexual asociado a la flaqueza de espíritu, por tanto, al pecado y a la putería. La tercera, se asocia a las virtudes, concretamente, a la maestría en la experiencia del oficio

Detengámonos en lo siguiente: lo que ha dado a Celestina sus virtudes y su vulnerabilidad de vieja han sido sus vicios. La vulnerabilidad es prácticamente una consecuencia de los vicios, pero que sus virtudes obedezcan a éstos es una paradoja. Cuando Celestina habla del deseo sexual de las mujeres, ella misma se pone como ejemplo. Asimismo, en sus pláticas con las mochachas y los criados, habla de la bonanza que, según dice, gozó en su juventud. Antes de ser alcahueta, habrá sido prostituta; después, prostituta y alcahueta, y ahora sólo alcahueta, pero sin dejar de ser una "puta vieja», como se lo confirma a Pármeno: «[...] tan puta vieja era tu madre como yo!» Así, parece que, para Celestina, la prostitución comenzó y se volvió oficio no por necesidad ni por sometimiento a un hombre, sino por gusto. Probablemente, de ahí la narración de una vida pasada 
exitosa y feliz. Esto despunta dos sentidos relacionados con sus vicios: por un lado, si bien estos vicios la han convertido en una vieja vulnerable, al mismo tiempo la han hecho virtuosa en experiencia; de ahí que gracias a ellos sobreviva. Por otro lado, si su juventud fue la mejor etapa de su vida, marcada por la prolijidad como prostituta, los vicios de Celestina se vuelven virtudes femeninas: al ser una experta virtuosa en las artes amatorias, ha reconocido que no hay diferencia entre prostitutas, alcahuetas o doncellas guardadas. Ante el deseo sexual, todas, dice ella, se vuelven valientes y esforzadas. Así, Celestina demuestra a Sempronio que no fallará en el negocio de Melibea.

Sin embargo, al inicio del cuarto auto, caminando en soledad hacia la casa de Pleberio, Celestina va aterrada. La alcahueta ha dado buenas razones para demostrar que cumplirá su cometido, ha conjurado al diablo, y, no obstante, está dudosa de su éxito. ¿Acaso el campo semántico de la vulnerabilidad es efectivo en ella? ¿Esto la hace dudar no sólo de sus artes hechiceriles y argumentativas, incluso de su poder para conjurar y amenazar al demonio? Considero que sí. En relación con el comentario de Fray Martín de Castañeda sobre la propensión de las viejas al demonio por causa de sus debilidades, Rafael Salillas habla de la vejez como el carácter más señalado de la bruja. "Será esto, [dice Salillas], seguramente, porque en la vejez se da el mayor conjunto de condiciones negativas. Es la edad de la impotencia, de la inacción, del abandono, del encorvamiento, de la flaqueza física, de la invalidez, de la miseria, de la esterilidad» (Salillas 1905). Aunque no podemos decir que Celestina es una bruja, sin duda, es este sentimiento de vulnerabilidad por causa de la vejez lo que la hace dudar de su poder. Tanto así que, ante su sensación de indefensión, evoca los posibles insultos de Calisto si ella se arrepintiera de entrar en casa de Melibea: "Diráme en mi cara denuestos rabiosos: 'tú, puta vieja [...] ¡Alcahueta falsa! [...] vieja traydora [...]. Pues no habiendo efeto, ni tú carecerás de pena ni yo de triste desesperación’ ¡Pues, triste yo!» (Iv, 299-300). Los insultos están relacionados con las connotaciones negativas de la vejez vistas al inicio de este análisis, según los autores, los criados y el eco de la gente. A pesar de que Celestina misma se reconoce ante Pármeno como "puta vieja», queda claro en su monólogo que, verdaderamente, repudia la asociación de su vejez con la falsedad de su oficio; no soporta el sentido peyorativo que adquieren su alcahuetería y su putería en las hipotéticas palabras de Calisto. De ahí que, en sus propias palabras, haya decidido "poner su persona al tablero".

Por último, me interesa mencionar qué sucede con Celestina antes de su muerte. En este momento, opera en ella principalmente el campo semántico de la vulnerabilidad a través de dos caminos. Uno manipulado por ella, el cual corresponde a las menciones de ella misma como una pobre y honrada vieja vulnerable ante la agresividad de Pármeno y Sempro- 
nio. El otro, encarnado en ella, corresponde al resultado de su situación de pobreza y de carencias; por supuesto, me refiero a la codicia.

Hemos revisado tres momentos en los que Celestina puede modificar en su favor las connotaciones negativas que recaen sobre la situación de su vejez. Pero en esta ocasión, no es así. Tal y como Sempronio y Pármeno la nombran, se comporta. Es decir, sabemos que los criados vienen a pedir su parte de la paga. Además, están alterados, pues no han dormido durante la noche por acompañar a Calisto a ver a Melibea. Asimismo, sospechan sobre la posibilidad de que la alcahueta no quiera compartir el botín. Con esto, podemos decir que hay una predisposición gradual en ellos a reaccionar con ira ante la manipulación de Celestina:

PAR.- ¿Adónde yremos, Sempronio? ¿A la cama a dormir o a la cozina a almorzar?

SEM.- Ve tú donde quisieres; que antes que venga el día quiero yo yr a Celestina a cobrar mi parte de la cadena. Que es una puta vieja; no le quiero dar tiempo en que fabrique alguna ruyndad con que nos escluya (XII, 475).

Joseph Snow señala que esta predisposición es originariamente causada en Pármeno y Sempronio por la misma Celestina, y casi desde el principio de la Tragicomedia a través de las dos «confederaciones» que ella crea para cumplir con la petición de Calisto: la primera, entre los dos criados y ella; y la segunda, y sin ella darse cuenta, la que crean Sempronio y Pármeno. Según Snow, la razón por la cual Celestina crea la primera confederación obedece, podemos decir, a todo lo que tiene que ver con el campo semántico de la vulnerabilidad revisado aquí: Celestina, disminuida en sus oficios por la pobreza y la vejez, se ve obligada a apoyarse en los criados. Pero sin darse cuenta, al reunirlos a ellos a lo largo del negocio de Calisto, hace que Sempronio y Pármeno creen una nueva confederación en su contra, pues nunca se percata de que estos dos conocen y están siempre pendientes de sus dobles intenciones. Es por ello que casi adivinan que la vieja avara no querrá darles su parte de la paga, y por eso ella misma los lleva a asesinarla:

En otras palabras [dice Snow] creo que Celestina no hubiera sido asesinada si no hubiera sentido la necesidad de una colaboración — confederación - con Sempronio y Pármeno. Lleva años Celestina como mujer profesional y orgullosa sin sufrir amenazas para con su vida, y en el acto IX se siente cerca de su fin, pero por su edad y por unos cambios radicales de su fortuna. Lo que es nuevo y contribuye a la sorprendente y no esperada forma de su muerte es el haberse confederado en el auto primero con dos sirvientes separados por tensiones y celos en 
contra de Calisto para ganar y compartir los tres. Lo que ella hace posible -irónicamente- es la anulación de las diferencias entre sus confederados y un nuevo compañerismo y hermandad de estos (la confederación de dos), antes enemistados criados, en contra de Calisto (por ganancias) como contra ella (por el prometido reparto del botín) (2013: 135).

Efectivamente, en cuanto los criados piden su parte de la cadena, Celestina se niega a dárselas. Por un lado y orgullosa de su trabajo, menciona Snow, arguye que el verdadero trabajo lo ha hecho ella; por otro, miente inventando que Elicia ha perdido la cadena; finalmente, cuando la vieja desata de manera definitiva e involuntaria la reacción agresiva e incontenible de los criados, apela, justo, al campo semántico de la vulnerabilidad con un poco del concerniente a sus virtudes:

CEL.- [...] ¿Estás en tu seso, Sempronio? ¿Qué tiene que hazer tu galardón con mi salario, tu soldada con mis mercedes? ¿Só yo obligada a soldar vuestras armas, a cumplir vuestras faltas? [...] Tengo, hijo, en buena fe, más pesar, que se me quiere salir esta alma de enojo. Di a esta loca de Elicia, como vine de tu casa, la cadenilla que traxe, para que se holgasse con ella, y no se puede acordar dónde la puso. Que en toda esta noche ella ni yo no avemos dormido sueño, de pesar.

$[\ldots]$

Qué quieren decir tales amenazas en mi casa? ¿Con una oveja mansa tenés vosotros manos y braveza? ¿Con una gallina atada? ¿Con una vieja de sesenta años?

Como lo señala Sempronio, la manipulación que de ellos intenta hacer aquí Celestina esconde tras de sí su codicia:

SEM.- No es ésta la primera vez que yo he dicho quánto en los viejos reyna este vicio de cobdicia: quánto pobre, franca; quando rica, avarienta.

Este hecho la ciega, pues se comporta al margen de la peligrosidad de la situación. Además de que, como menciona Snow, no ha sido capaz de reconocer que su confederación inicial ha fracasado por causa de ella misma y en favor de la nueva, la que sólo involucra a Sempronio y a Pármeno. No parece percatarse de esta situación y de que su codicia, defecto propio de los viejos, y en particular, de una vieja alcahueta que lo ha perdido casi todo por sus defectos/virtudes, la deja completamente vulnerable, expuesta ante sus agresores. Además, puesto que no repara en la falta de efectividad de sus palabras en tal contexto, fracasa inminentemente 
tras su irrisorio intento de manipulación verbal hacia los criados. Así, en tal situación, la más grave de todas para Celestina, la vieja es ya incapaz de transformar los sentidos negativos de los atributos que rodean la idea de su vejez. Irónicamente, la alcahueta finge vulnerabilidad; sin embargo, no se da cuenta de que, con tal fingimiento, en realidad se está mostrando todavía más como "presa fácil» de aquellos a los que ha intentado manipular. Ya es demasiado tarde para ella:

CEL.- [...] Si aquella que allí está en aquella cama me oviesse a mí creýdo, jamás quedaría esta casa de noche sin varón, ni dormiríemos a lumbre de pajas; pero por aguardarte, por serte fiel, padescemos esta soledad. Y, como nos veys mujeres, habláis y pedís demasías. Lo qual, si hombre sintiéssedes en la posada, no haríades;

SEM.- ¡O vieja avarienta, garganta muerta de sed por dinero! ¿No serás contenta con la tercia parte de lo ganado? CEL.- ¿Qué tercia parte? Vete con Dios de mi casa, tú. Y essotro no dé vozes, no allegue la vecindad. No me hagáis salir de seso. No queráis que salgan a plaza cosas de Calisto y vuestras.

SEM.- Da vozes o gritos, que tú complirás lo que tú prometiste, o se complirán oy tus días. (XII, 484-485).

Para concluir, podemos reafirmar la presencia de la tradición misógina en la configuración de Celestina a partir del saber científico de su época, así como del imaginario popular. No obstante, esta perspectiva no coincide con la que Celestina tiene de sí misma; que como vimos, es la de sus interlocutores, la de la voz popular y, aparentemente, la de los autores de la Tragicomedia. Se podría decir que la forma en que la vieja manipula verbalmente el sentido de sus atributos es una muestra de sus habilidades de "falsa mujer hechizera" para engañar a la gente, salvo en el caso de todo aquello que la lleva a trazar el camino de su propia muerte. Sin embargo, en esta discusión no podemos perder de vista las cualidades perspectivistas del presente diálogo; éstas otorgan generosamente, en este caso a Celestina, la libertad para concebirse a sí misma y frente los demás como a ella le plazca. Con ello, en momentos claves la alcahueta es capaz de destruir las connotaciones negativas que caen sobre su repulsiva vejez. Más aún, destruye la tesis de que la mujer es presa de la maldad y la lujuria por causa de su flaqueza espiritual. Celestina propone, así, que la sexualidad femenina, lejos de ser un defecto moral, es una virtud que hace a todas las mujeres "enemigas del medio; [y estar] contino posadas en los estremos» (III, 288). 


\section{Bibliografía citada}

Blanco, Juan Francisco. Brujería y otros oficios populares de la magia. Valladolid: Ámbito, 1992.

Castañega, Fray Martín de. Tratado de las supersticiones y hechicerías. Fabián Alejandro Compagne (ed.). Buenos Aires: Universidad de Buenos Aires. Colección de Libros Raros, Olvidados y Curiosos, 1997.

CoHen, Esther. Con el diablo en el cuerpo. Filósofos y brujas en el renacimiento. México: Instituto de Investigaciones Filológicas-UNAM-Taurus, 2003.

Deyermond, Alan. "Hacia una lectura feminista de La Celestina», en Medievalia. Estudios de Alan Deyermond sobre la 'Celestina'. 40. México: Instituto de Investigaciones Filológicas, 2008, 74-85.

RojAs, Fernando de. Comedia o Tragicomedia de Calisto y Melibea. Peter E. Russell (ed.). Madrid: Castalia, 2001.

Salillas, Rafael. La fascinación en España. Brujas, brujería y amuletos. Madrid: Imprenta a cargo de Eduardo Arias, 1905. <https://archive.org/ lafascinenes00sali/lafascinacinenes00sali_djvu.txt>.

SAnz, Jacobo. "Una vieja barbuda que se dice Celestina: Notas acerca de la primera caracterización de Celestina», en Celestinesca. 18-1 (Primavera) Valencia: Universitat de València, 1994, 18-34.

Snow, Joseph T. "Confederación e ironía: crónica de una muerte anunciada (Celestina, autos I-XII)", en Celestinesca. 37, Valencia: Universitat de València, 2013, 119-138.

Von der WALde, Lillian. «El cuerpo de Celestina: un estudio sobre fison mía y personalidad», en Humanista. 9, Santa Bárbara, CA: Universidad de California, 2007, 129-142. 



\section{Gómez Goyzueta, Ximena, «De viva y vieja voz: Celestina por sí misma», Celestinesca 40 (2016), pp. 73-86.}

\section{RESUMEN}

En su artículo "Hacia una lectura feminista en La Celestina», Alan Deyermond cuestiona lo siguiente: "[...] habrá que preguntarse si la representación de la hechicería/brujería de Celestina [...] por Fernando de Rojas y su predecesor anónimo se debe explicar en términos de la represión misógina». En mi opinión, la respuesta es negativa. El trabajo que propongo consiste en mostrar que la configur ción de Celestina tiende principalmente hacia la caracterización de una alcahueta ficticia, más que a ser concebida desde una perspectiva misógina. A partir de esta respuesta, analizo las formas en las que Celestina es nombrada en los paratextos y por los demás personajes; con ello, me propongo identificar el retrato ficticio de la alcahueta que construyen los autores del texto salmantino. Asimismo, observo cómo la naturaleza perspectivista del diálogo celestinesco permite, a su vez, que Celestina sea capaz de autoconcebirse en la ficción como mejor le convenga, y crear, así, su propio retrato más allá de las miradas de los demás.

PALABRAS ClaVE: Perspectivismo, vejez, virtudes, vicios, vulnerabilidad.

\section{ABSTRACT}

In his article "Hacia una lectura feminista en La Celestina», Alan Deyermond questions as follows: «[...] habrá que preguntarse si la representación de la hechicería/ brujería de Celestina [...] por Fernando de Rojas y su predecesor anónimo se debe explicar en términos de la represión misógina». In my opinion, the answer is no. The work that I propose is to show that the configuration of Celestina tends mainly to the characterization of a fictional bawd, rather than being conceived from a misogynistic perspective. From this response, I analyze the ways in which Celestina is named in the paratexts and other characters; thus I intend to identify the fictional portrait of the bawd who build the authors of salmantino text. I also note how the perspectival nature of the dialogue Celestina allows, in turn, to be able to conceive herself in fiction as she wishes, and thus create her own portrait beyond the eyes of others.

KEY WORDS: Perspectivism, Old Age, Virtues, Vices, Vulnerability

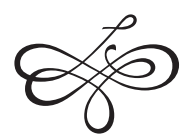

